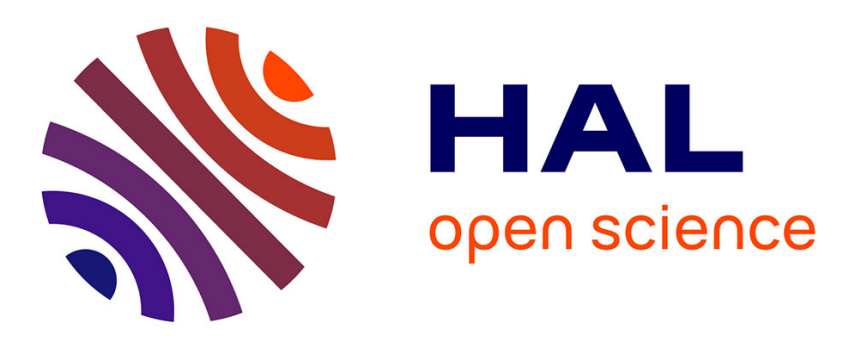

\title{
Silyl Radical Mediated Cross-Electrophile Coupling of N -Acyl-imides with Alkyl Bromides under Photoredox/Nickel Dual Catalysis
}

Taline Kerackian, Antonio Reina, Didier Bouyssi, Nuno Monteiro, Abderrahmane Amgoune

\section{- To cite this version:}

Taline Kerackian, Antonio Reina, Didier Bouyssi, Nuno Monteiro, Abderrahmane Amgoune. Silyl Radical Mediated Cross-Electrophile Coupling of N -Acyl-imides with Alkyl Bromides under Photoredox/Nickel Dual Catalysis. Organic Letters, 2020, 22 (6), pp.2240-2245. 10.1021/acs.orglett.0c00442 . hal-03007612

\section{HAL Id: hal-03007612 \\ https://hal.science/hal-03007612}

Submitted on 17 Nov 2020

HAL is a multi-disciplinary open access archive for the deposit and dissemination of scientific research documents, whether they are published or not. The documents may come from teaching and research institutions in France or abroad, or from public or private research centers.
L'archive ouverte pluridisciplinaire HAL, est destinée au dépôt et à la diffusion de documents scientifiques de niveau recherche, publiés ou non, émanant des établissements d'enseignement et de recherche français ou étrangers, des laboratoires publics ou privés. 


\title{
Silyl radical mediated cross-electrophile coupling of $\mathrm{N}$-acyl- imides with alkyl bromides under photoredox/nickel dual catalysis
}

\author{
Taline Kerackian,$\uparrow$ Antonio Reina,$\dagger$ Didier Bouyssi,$\uparrow$ Nuno Monteiro,$\dagger$ Abderrahmane Amgoune $* \dagger$ \\ $\dagger$ Univ Lyon, Université Lyon 1, Institut de Chimie et Biochimie Moléculaires et Supramoléculaires, UMR 5246 du CNRS. \\ 1, rue Victor Grignard, 69100 Villeurbanne (France). \\ $\$$ Institut Universitaire de France (IUF), 1 rue Descartes, 75231 Paris, (France)
}

\begin{abstract}
A photoredox Ni-catalyzed cross-coupling of $N$-acyl-imides with unactivated alkyl bromides has been developed that enables efficient access to a variety of functionalized alkyl ketones, including unsymmetrical dialkyl ketones, under very mild and operationally practical conditions. The reaction that operates without the need for any preformed carbon nucleophile proceeds via the combination of two different bond activation processes, i.e. Ni-catalyzed imide activation via $C(a c y l)-N$ bond cleavage, and $(T M S)_{3}$ Si radical-mediated alkyl halide activation via halogen-atom abstraction.
\end{abstract}

\begin{abstract}
Transition metal-catalyzed acylation of organometallic compounds is a well-established key transformation in organic chemistry that is of high relevance to the synthesis of a plethora of carbonyl-containing compounds, including ketones. ${ }^{1}$ Besides classical acyl-transfer reagents (e.g., acyl chlorides, anhydrides, and thioesters) that are typically employed in these reactions, resonance destabilized amides have recently emerged as new potent electrophiles. These bench-stable acyl electrophiles are equally well accessible from abundant carboxylic acids, and have been shown to engage in cross-coupling reactions with organometallic nucleophiles. ${ }^{2}$ Nickel catalysis has been particularly highlighted as a very powerful strategy to forge $\mathrm{C}(\mathrm{acyl})-\mathrm{C}\left(\mathrm{sp}^{2}\right)$ bonds via $\mathrm{C}-\mathrm{N}$ bond activation of amides, allowing the efficient preparation of valuable ketones. ${ }^{3}$ While the remarkable properties of nickel ${ }^{4}$ unlocked the development of challenging cross-coupling reactions with $\mathrm{C}\left(\mathrm{sp}^{3}\right)$-hybridized substrates, ${ }^{4 a}$ it is striking to note that the conversion of amides to alkyl ketones via $\mathrm{C}(\mathrm{acyl})-\mathrm{C}\left(\mathrm{sp}^{3}\right)$ bond formation remains extremely rare. It is even more surprising that it could provide convenient synthetic methods to this versatile class of carbonyl compounds with notable applications spanning drug lead and natural product synthesis, as well as

groups of McMillan, Doyle ${ }^{12}$ and Molander, ${ }^{13}$ nickel/photoredox dual catalysis has bourgeoned into one of the most appealing strategies for introducing $\mathrm{C}\left(\mathrm{sp}^{3}\right)$-centers onto organic frameworks under very mild reaction conditions. ${ }^{14}$ This new methodology exploits the inherent ability of nickel complexes to undergo single electron transfer and accept alkyl radical species, issued here from a photoredox cycle. A tremendous progress has been made recently in this field by the group of MacMillan, ${ }^{15}$ with the sophisticated design of a nickel/photoredox cross-electrophile coupling of two organobromides. The key point of the mechanistic design relied on the documented ability of silyl radical intermediates, that are photocatalytically generated, to activate an alkyl bromide via halogenatom abstraction. ${ }^{16}$ This procedure enables efficient $\mathrm{C}\left(\mathrm{sp}^{2}\right)$ $\mathrm{C}\left(\mathrm{sp}^{3}\right)$ bond formation without the need for any preformed carbon nucleophiles. ${ }^{17}$ Inspired by this seminal breakthrough, we report herein the successful application of silyl radicalmediated activation of alkyl bromides to the development of a catalytic cross-electrophile coupling of amides with alkyl bromides. This method provides facile access to alkyl ketones, including primary and secondary alkyls, under very mild conditions.
\end{abstract} for their propensity to undergo functional group interconversion. The very few examples documented so far consist of nickel-catalyzed cross-couplings with organometallic reagents that are reminiscent of Negishi and Suzuki reactions. For instance, Garg and co-workers reported the acylation of alkylzinc reagents with $N$-tosyl and $N$-Boc amides. ${ }^{5}$ The group of Rueping investigated the cross-coupling of $N$-(Me)Ph amides with alkylboranes. ${ }^{6}$ In a different approach, Molander and coworkers developed the cross-coupling of $N$-acyl-succinimides with alkyltrifluoroborates via single-electron transmetalation with the aid of visible-light mediated photoredox catalysis (Scheme 1a).7,8

Another highly valuable, yet unknown, strategy to convert amides into alkyl ketones would involve direct cross-electrophile coupling with abundant and bench stable alkyl halide electrophiles, avoiding the use of organometallic reagents. ${ }^{9}$ Cross-coupling reactions between two electrophiles have rapidly developed as a very appealing method to forge carboncarbon bonds starting from alkyl halide reagents..$^{10}$ For the preparation of ketones, reported methods rely on nickel catalyzed reductive acyl cross coupling between aroyl chlorides or anhydrides with alkyl halides, and require a stoichiometric amount of metal reductants. ${ }^{11}$ In this work, we aimed to develop a direct cross-coupling of amides with alkyl bromides under mild conditions using cooperative nickel and photoredox catalysis (Scheme 1b). Since its introduction in 2014 by the

Scheme 1. Ni-catalyzed C(acyl)-C( $\left.\mathrm{sp}^{3}\right)$ cross-coupling reactions of amide-derived electrophiles. 


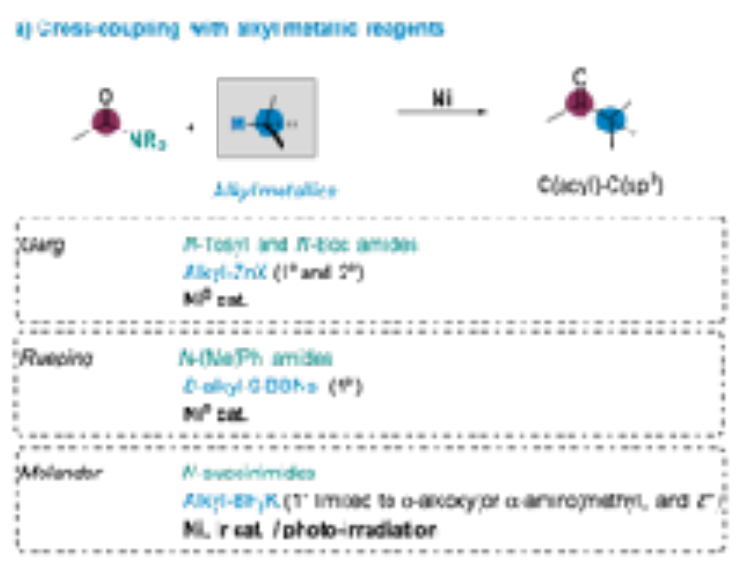

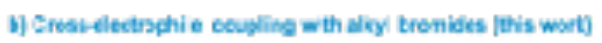

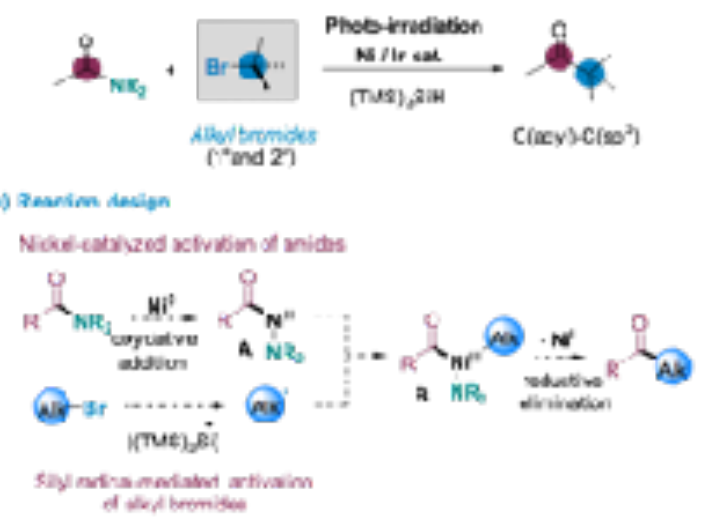

The reaction design relies on the combination of two distinct modes of bond activation: (i) $\mathrm{C}($ acyl)-N bond activation of the amide via oxidative addition to $\mathrm{Ni}(0)$ catalyst, and (ii) $\mathrm{C}(\mathrm{alkyl})-\mathrm{Br}$ activation of the alkyl bromide via halogen-atom abstraction by a stabilized (TMS) ${ }_{3} \mathrm{Si}$ radical, deriving from photocatalytic activation of tris(trimethylsilyl)silane $\left[(\mathrm{TMS})_{3} \mathrm{SiH}\right] .{ }^{16}$ These two activation processes would then merge through the capture of the alkyl radical by the acyl$\mathrm{Ni}(\mathrm{II})$ complex (A), which would then be followed by C(alkyl)-C(acyl) reductive elimination from high-valent $\mathrm{Ni}(\mathrm{III})$-amidate complex (B) (Scheme 1c). In this process, the photocatalyst would be required for the generation of the silyl radical species, and for reducing $\mathrm{Ni}(\mathrm{I})$ to $\mathrm{Ni}(0)$ so as to restart the nickel catalytic cycle.

We began our study with the reaction of $N$-benzoyl-succinimide ${ }^{18}$ 1aa with 4-bromotetrahydropyran 2a in the presence of stoichiometric amount of [(TMS) $\left.)_{3} \mathrm{SiH}\right]$ to assess the feasibility of the process. The selected dual catalytic system was composed of the bench-stable $\left[\mathrm{Ni}(\mathrm{dtbbpy})\left(\mathrm{H}_{2} \mathrm{O}\right)_{4}\right] \mathrm{Cl}_{2}$ complex $\mathbf{I}$, and $\operatorname{Ir}\left[\left(\mathrm{dF}_{(}\left(\mathrm{CF}_{3}\right) \text { ppy }\right)_{2}(\mathrm{dtbbpy})\right] \mathrm{PF}_{6}$ complex II as the photocatalyst (Table 1).

Table 1. Selected preliminary optimization experiments ${ }^{[a]}$

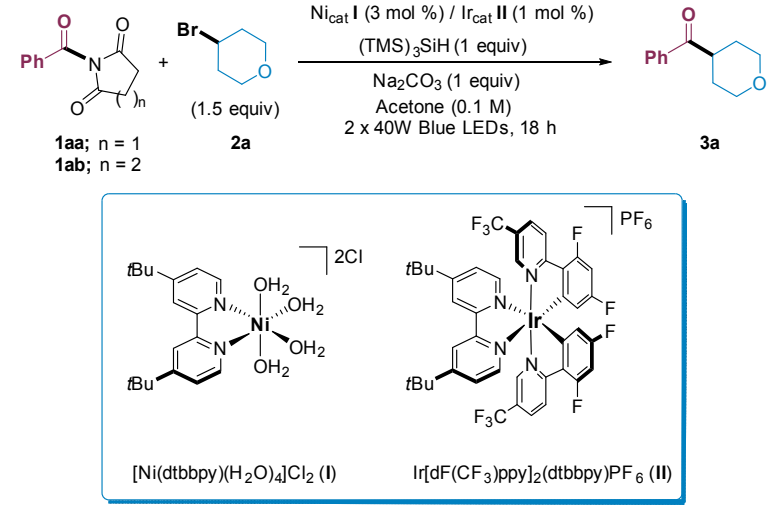

\begin{tabular}{|c|c|c|}
\hline Entry & Deviation from optimal reaction conditions & Yield (\%)[b] \\
\hline 1 & none & $74(59)$ \\
\hline 2 & $48 \mathrm{~h}$ with one $30 \mathrm{~W}$ hlıe I FD lamn [c] & 76 \\
\hline 3 & EtOAc as solvent & $57[d]$ \\
\hline 4 & $72 \mathrm{~h}$ with one $30 \mathrm{~W}$ blue LED lamp in EtOAc [c] & 74 \\
\hline 5 & no hase & 0 \\
\hline 6 & no photocatalyst & 0 \\
\hline 7 & no light (dark) & 0 \\
\hline 8 & no Ni catalyst & 0 \\
\hline 9 & no silane & 0 \\
\hline 10 & $0.5 \mathrm{~mol} \%$ of photocatalyst II & 66 \\
\hline 11 & $\mathrm{Ni}(\mathrm{COD}))_{2} / \mathrm{dth}$ thy instead of I & 63 \\
\hline 12 & $0.5 \mathrm{~mol} \%$ of Ni complex I, $24 \mathrm{~h}$ & 61 \\
\hline 13 & Glutarimide derivative $\mathbf{1} \mathbf{a b}$ as substrate & 68 \\
\hline 14 & $\mathrm{NaBr}$ instead of $\mathrm{Na}_{2} \mathrm{CO}_{3}$ & 7 \\
\hline 15 & $\mathrm{NaBr}$ additive (1 equiviv) & 69 \\
\hline
\end{tabular}

[a] I Jnless ntherwise stated, reactions were performed using $N$-acylsuccinimide 1 aa on a $0.5 \mathrm{mmol}$ scale under the irradiation of two $40 \mathrm{~N}$ blue LED Kessil ${ }^{\circledR}$ lamps $(455 \mathrm{~nm})$. See the Supporting Information for details regarding lighting set-ups. Dtbbpy $=4,4$ '-di-tert-butyl-2 2"dipyridyl; ppy = 2-phenylpyridine. [b] Yields were determined by 1 H NMR dipyridyl; ppy = 2-phenylpyridine. [b] Yields were determined by ${ }^{\prime} \mathrm{H}$ NMR spectroscopy using dibromomethane as an internal standard. Yields in parentheses refer to isolated pure compound. [c] Reaction performetd using EvoluChem ${ }^{\mathrm{TM}}$ PhotoRedOx Box device equipped with one $30 \mathrm{~N}$ LED lamp $(450 \mathrm{~nm})$. [d] At this point (after $18 \mathrm{~h}$ ) c.a. $20 \%$ of unreacte $\mathrm{d}$ starting imide was still present in the reaction mixture.

A brief survey of several solvents (e.g., DME, 1,4-dioxane, 2MeTHF, MeCN, DMF, DCM, acetone, ethyl acetate) and bases (e.g., alkali carbonates, $\mathrm{K}_{3} \mathrm{PO}_{4}, \mathrm{CsF}, \mathrm{AcONa}, \mathrm{Et}_{3} \mathrm{~N}, 2$, 6lutidine), revealed that the desired alkyl ketone 3a could be obtained in good yields with sodium carbonate as the base, and acetone or ethyl acetate as the solvent (Table 1, entries 3-4). ${ }^{19}$ Evaluation of the blue LED light irradiation setting indicated that the transformation proceeds equally well using direct irradiation with two 40W blue LED Kessil@ lamps (455 nm) $(74 \%$ yield, $18 \mathrm{~h})$ or using the EvoluChem ${ }^{\mathrm{TM}}$ PhotoRedOx Box device equipped with one $450 \mathrm{~nm} 30 \mathrm{~W}$ blue LED lamp ( $76 \%$ yield, albeit in $48 \mathrm{~h}$ ). Control experiments revealed that the dual catalytic system, silane, base and light irradiation are essential for this transformation (Table 1, entries 5-9). From a practical point of view, it is interesting to note that the bench-stable $\mathrm{Ni}(\mathrm{II})$ complex I provides better results than the air-sensitive $\mathrm{Ni}(\mathrm{COD})_{2} /$ dtbbpy catalytic system (entry 11). Furthermore, the reaction proceeds well with very low nickel catalytic loading (down to $0.5 \mathrm{~mol} \%$, Table 1, entry 12). Finally, glutarimide derivative $\mathbf{1 a b}$ also proved to be a reactive substrate, affording 3a in $68 \%$ yield (Table 1, entry 13 ).

Table 2. Scope of alkyl bromides and imides.[a] 

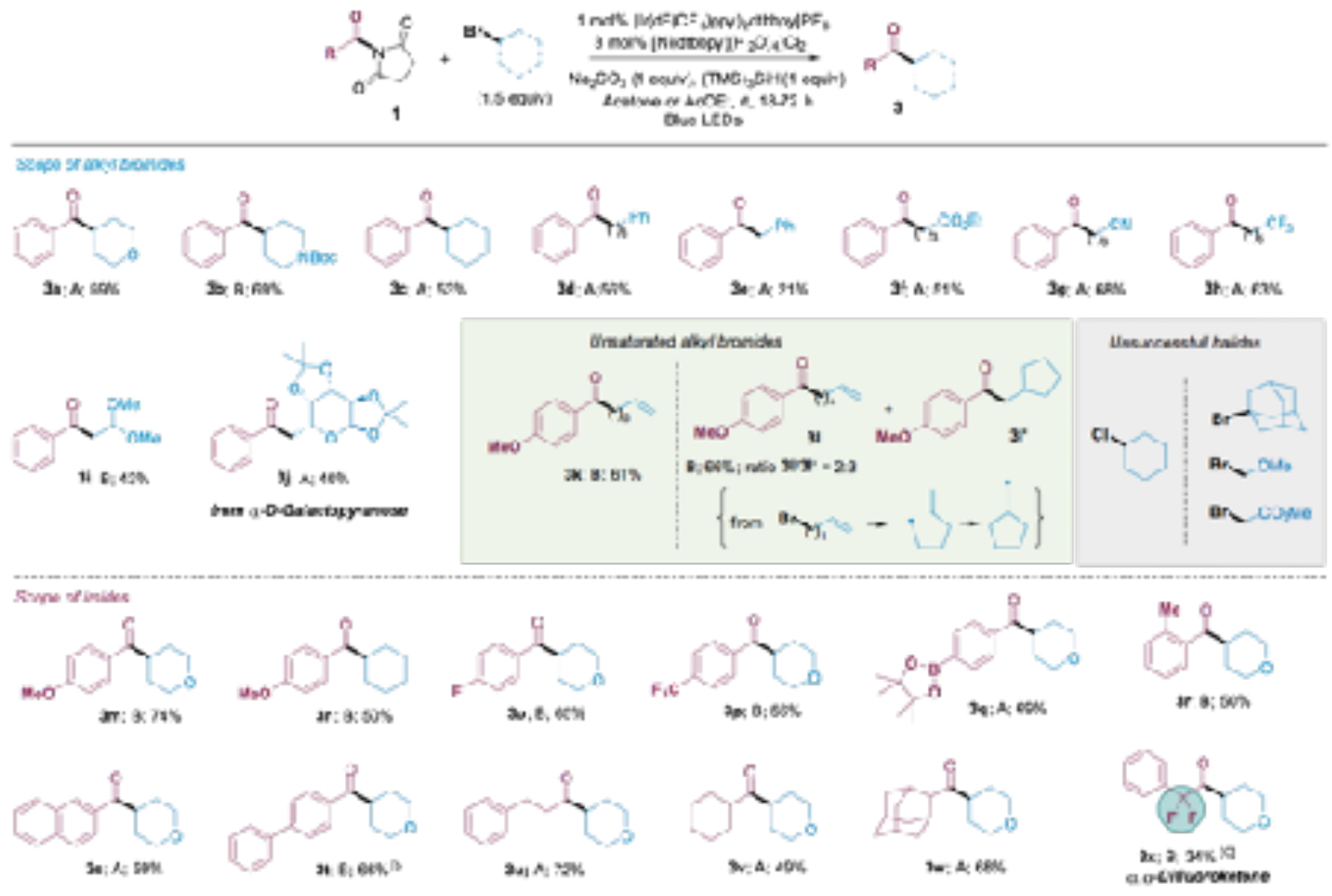

[a] Reactions performed on a $0.5 \mathrm{mmol}$ scale. Conditions A: Acetone was used as solvent under the irradiation of two 40W blue LED Kessil ${ }^{\circledR}$ lamps (455 nm) for 18-24 h; Conditions B: Ethyl acetate was used as solvent under the irradiation of a $30 \mathrm{~W}$ blue LED lamp (450 $\mathrm{nm}$ ) for 24-72 h using the EvoluChem ${ }^{\mathrm{TM}}$ PhotoRedOx Box device. Isolated yields are given. [b] The reaction was run in acetone. [c] Obtained from the corresponding $\mathrm{N}$-acylglutarimide.

With a set of suitable conditions in hand, we investigated the applicability of the methodology across a broad range of succinimide derivatives and commercially available alkyl halides (Table 2). The scope of alkyl bromides that underwent the transformation encompassed a range of primary and secondary non-activated derivatives, bearing a variety of functional groups such as ester, nitrile, amine, fluoroalkyl, ether as well as sensitive acetals (3a-3j). Notably, the protocol proved capable of delivering $\beta$-alkoxy-substituted ketones, including galactopyranose derivative $(\mathbf{3 j})$. On the other hand, alkylation using the activated $\alpha$-methoxymethyl bromide (MOMBr) failed to provide the corresponding $\alpha$-oxygenated ketone. Alkyl bromides bearing terminal alkene moieties were also suitable substrates. The cross-coupling reaction with 7-bromohept-1-ene afforded the expected coupling product in fair yield (3k) leaving the double bond untouched. In contrast, the 6hexen-1-yl homolog, as a radical-clock substrate, partially underwent 5-exo-trig cyclization, thus leading to a mixture of cyclic and linear cross-coupled products 31' and 31, respectively, with a ratio of $3: 2$. This observation provides strong support for the formation of alkyl radicals as intermediate species in the coupling process. Overall, the scope of reactive alkylbromides is complementary to that reported using alkyltrifluoroborates as radical precursors under a similar dual catalytic system.7,21 With respect to the scope of imide counterparts, the reaction protocol allowed the coupling of a variety of aromatic derivatives with various functional groups and substitution patterns (3m-3t), including boronic acid pinacol (BPin) ester (3q) that provides a chemical handle for further elaboration. Importantly, the scope was also expanded to imides having saturated backbones, thus providing access to unsymmetrical dialkyl ketones (3u-3w). Finally, access to $\alpha, \alpha$-difluoroketones was envisioned as a highly valuable addition to the scope of the reaction. Indeed, this would provide an attractive strategy for the direct difluoroacetylation of aliphatic backbones. However, $N$-( $\alpha, \alpha$-difluoroacetyl)-imides are challenging substrates that are vulnerable to decomposition when exposed to inorganic bases. ${ }^{22}$ Nevertheless, a promising preliminary result was obtained with the synthesis of $\alpha, \alpha$-difluoroalkylketone 3x. To further demonstrate the synthetic utility of the cross-coupling reaction, a synthesis of $\mathbf{3 a}$ was performed on a $1.5 \mathrm{mmol}$ scale, and the product was obtained in $49 \%$ isolated yield.

From a mechanistic point of view, in light of previous documented studies $7,15,17$ and our own observations, a sequence of events as depicted in Scheme 3 may be proposed as a possible reaction pathway. Nickel $(0)$ complex would undergo oxidative addition of the amide electrophile via $\mathrm{C}-\mathrm{N}$ bond cleavage. Meanwhile, the alkyl bromide would be activated by $(\mathrm{TMS})_{3} \mathrm{Si}$ radical through the generation of a nucleophilic alkyl radical with concomitant production of bromotris(trimethylsilyl)silane. Capture of the alkyl radical by the acyl-Ni(II) intermediate $\mathbf{A}$, followed by reductive elimination of the desired ketone from high-valent $\mathrm{Ni}$ (III)-amidate complex B would afford Ni(I)-amidate $\mathbf{C}$. Then, reduction of the $\mathrm{Ni}(\mathrm{I})$ species to $\mathrm{Ni}(0)$ by $\mathrm{Ir}(\mathrm{II})$ would restart the nickel and iridium catalytic cycles and liberate a succinimidate ligand. Importantly, silylated succinimide $\mathbf{4}$ could be identified as a co-product of the reaction. This hitherto unknown compound was isolated and characterized. It is most likely that it derives from nucleophilic substitution of the silyl bromide by succinimidate anion, ${ }^{23}$ thus terminating the silicon pathway. Concerning the generation of the (TMS $)_{3} \mathrm{Si}$ radical intermediate, two possible pathways may be envisioned. A single electron oxidation of released $\mathrm{Br}^{-}$anion by the photoexcited * $\operatorname{Ir}(\mathrm{III})$ catalyst would generate a bromine radical that can abstract hydrogen from (TMS) ${ }_{3} \mathrm{SiH}$ (not shown). ${ }^{14 a}$ However, it has to be noted that the addition of $\mathrm{NaBr}$ as a bromide source did not 
improve the reaction yield. Furthermore, only traces of the product were observed when $\mathrm{NaBr}$ was used instead of the base (Table 1, entries 14 and 15). Alternatively, the (TMS) ${ }_{3} \mathrm{Si}$ radical intermediate could be generated directly via oxidative scission of the (TMS) $)_{3} \mathrm{Si}-\mathrm{H}$ bond by the strongly oxidizing photoexcited * $\operatorname{Ir}(\mathrm{III})$ catalyst in the presence of a base (scheme 3). ${ }^{17 \mathrm{~d}, \mathrm{e}}$

Scheme 3. Tentative mechanism.

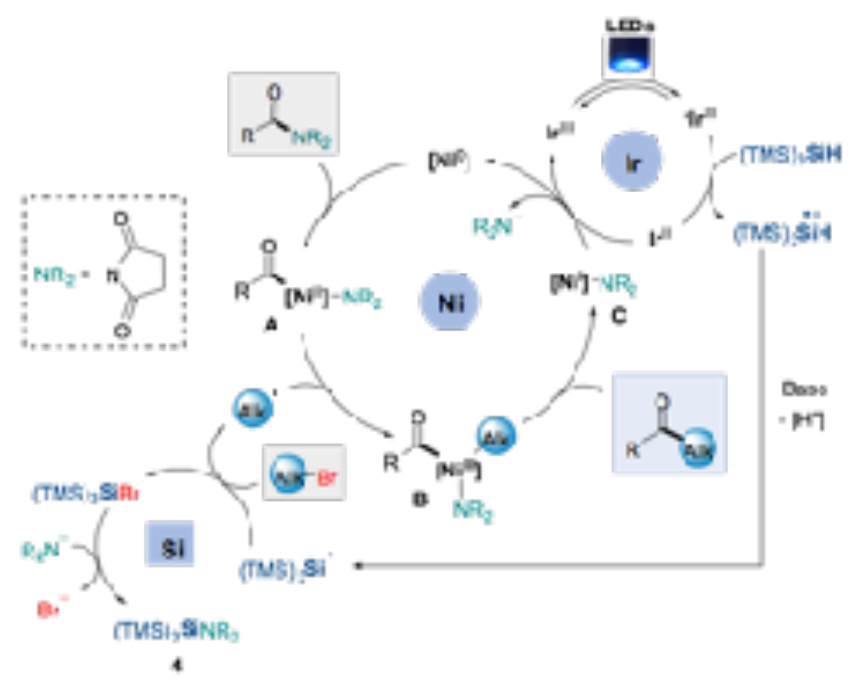

In summary, we have described a new cross-electrophile coupling reaction using $\mathrm{N}$-(acyl)-imides and alkyl bromides as readily available, bench stable coupling partners. The reaction was conducted under very mild and operationally simple conditions without the need for any air-free techniques. A wide range of substrates, including primary and secondary alkyl bromides as well as alkyl amides are reactive, underscoring the great value of this reaction for the synthesis of a variety of functionalized alkyl ketones

\section{ASSOCIATED CONTENT}

\section{Supporting Information}

The Supporting Information is available free of charge on the ACS Publications website.

Experimental procedures, compound characterization data, and NMR spectra (PDF)

\section{AUTHOR INFORMATION}

\section{Corresponding Author}

* E-mail: abderrahmane.amgoune@univ-lyon1.fr

\section{Notes}

The authors declare no competing financial interest.

\section{ACKNOWLEDGMENT}

Financial support from the Université de Lyon, IDEXLYON project (ANR-16_IDEX-0005), is gratefully acknowledged. T. K. thanks the French Ministry of Higher Education and Research for a doctoral fellowship.

\section{REFERENCES}

(1) Reviews: a) Dieter, R. K. Reaction of acyl chlorides with organometallic reagents: A banquet table of metals for ketone synthesis. Tetrahedron 1999, 55, 4177-4236. b) Gooßen, L. J.; Rodriguez, N.; Gooßen, K. Carboxylic acids as substrates in homogeneous catal- ysis. Angew. Chem., Int. Ed. 2008, 47, 3100-3120. c) Buchspies, J.; Szostak, M. Recent advances in acyl Suzuki cross-coupling. Catalysts 2019, 9, 53.

(2) Reviews: a) Meng, G.; Shi, S.; Szostak, M. Cross-coupling of amides by N-C bond activation. Synlett 2016, 2530-2540. b) Takise, R.; Muto, K.; Yamaguchi, J. Cross-coupling of aromatic esters and amides Chem. Soc. Rev. 2017, 46, 5864-5888. c) Chaudhari, M. B.; Gnanaprakasam, B. Recent advances in the metal-catalyzed activation of amide bonds. Chem. Asian J. 2019, 14, 76-93.

(3) Dander, J. E.; Garg, N. K. Breaking amides using nickel catalysis. ACS Catal. 2017, 7, 1413-1423.

(4) a) Hu, X. Nickel-catalyzed cross coupling of non-activated alkyl halides: a mechanistic perspective. Chem. Sci. 2011, 2, 1867-1886. b) Tasker, S. Z.; Standley, E. A.; Jamison, T. F. Recent advances in homogeneous nickel catalysis. Nature 2014, 509, 299-309. c) Ananikov, V. P. Nickel: The "spirited horse" of transition metal catalysis. ACS Catal. 2015, 5, 1964-1971. d) Diccianni, J. B.; Diao, T. Mechanisms of nickel-catalyzed cross-coupling reactions. Trends in Chemistry 2019, 1, 830-844.

(5) Simmons, B. J.; Weires, N. A.; Dander, J. E.; Garg, N. K. Nickelcatalyzed alkylation of amide derivatives. ACS Catal. 2016, 6, 3176-3179.

(6) a) Liu, X.; Hsiao, C-C.; Guo, L.; Rueping, M. Cross-coupling of amides with alkylboranes via nickel-catalyzed $\mathrm{C}-\mathrm{N}$ bond cleavage. Org. Lett. 2018, 20, 2976-2979; For a very similar methodology using palladium catalysts, see b) Meng, G.; Szostak, M. Palladium/NHC (NHC $=N$-Heterocyclic Carbene)-catalyzed B-alkyl Suzuki crosscoupling of amides by selective $\mathrm{N}-\mathrm{C}$ bond cleavage. Org. Lett. 2018, 20, 6789-6793.

(7) Amani, J.; Alam, R.; Badir, S.; Molander, G. A. Synergistic visible-light photoredox/nickel-catalyzed synthesis of aliphatic ketones via N-C cleavage of imides. Org. Lett. 2017, 19, 2426-2429.

(8) The same methodology has been successfully applied to the acylative cross-coupling of acyl chlorides or anhydrides with boron or silicon based nucleophiles, see: (a) Amani, J.; Sodagar, E.; Molander, G. A. Visible light photoredox cross-coupling of acyl chlorides with potassium alkoxymethyl trifluoroborates: Synthesis of $\alpha$-alkoxy ketones. Org. Lett. 2016, 18, 732-735. (b) Amani, J.; Molander, G. A. Synergistic photoredox/nickel coupling of acyl chlorides with secondary alkyltrifluoroborates: Dialkyl ketone synthesis. J. Org. Chem. 2017, 82, 1856-1863. (c) Amani, J.; Molander, G. A. Direct Conversion of Carboxylic Acids to Alkyl Ketones. Org. Lett. 2017, 19, 36123615. (d) Levernier, E.; Corcé, V.; Rakotoarison, L. M.; Smith, A.; Zhang, M.; Ognier, S.; Tatoulian, M.; Ollivier, C.; Fensterbank, L. Cross coupling of alkylsilicates with acyl chlorides via photoredox/ nickel dual catalysis: a new synthesis method for ketones. Org. Chem. Front. 2019, 6, 1378-1382.

(9) For a previous article reporting $N$-acyl-imides as electrophiles, but involving aryl iodides as coupling partners, see: a) Ni, S.; Zhang, W.; Mei, H.; Han, J.; Pan, Y. Ni-catalyzed reductive cross-coupling of amides with aryl iodide electrophiles via $\mathrm{C}-\mathrm{N}$ bond activation. Org. Lett. 2017, 19, 2536-2539. At the time of submission of the present manuscript, Matsuo and co-workers published a reductive cross-coupling strategy making use of Katritzky salts as alkyl radical precursors; b) Yu, C.-G.; Matsuo, Y. Nickel-catalyzed deaminative acylation of activated aliphatic amines with aromatic amides via $\mathrm{C}-\mathrm{N}$ bond activation. Org. Lett. 2020, 22, 950-955.

(10) For reviews of cross-electrophile coupling strategies, see: a) Everson, D. A.; Weix, D. J. Cross-electrophile coupling: Principles and selectivity. J. Org. Chem. 2014, 79, 4793-4798. b) Weix, D. J. Methods and mechanisms for cross-electrophile coupling of $\mathrm{Csp}^{2}$ halides with alkyl electrophiles. Acc. Chem. Res. 2015, 48, 1767-1775. c) Knappke, C. E. I.; Grupe, S.; Gärtner, D.; Corpet, M.; Gosmini, C.; Jacobi von Wangelin, A. Reductive Cross-Coupling Reactions between Two Electrophiles. Chem. Eur. J. 2014, 20, 6828-6842. d) Gu, J.; Wang, X.; Xue, W.; Gong, H. Nickel-catalyzed reductive coupling of alkyl halides with other electrophiles: concept and mechanistic considerations. Org. Chem. Front. 2015, 2, 1411-1421.

(11) Review: (a) Moragas, T.; Correa, A.; Martin, R. Metal-catalyzed reductive coupling reactions of organic halides with carbonyl-type 
compounds. Chem. Eur. J. 2014, 20, 8242-8258. For recent examples of Ni-catalyzed reductive cross-electrophile coupling reactions of acyl halides, anhydrides or esters with alkyl halides, see: (b) Yin, H.; Zhao, C.; You, H.; Lin, K.; Gong, H. Mild ketone formation via Ni-catalyzed reductive coupling of unactivated alkyl halides with acid anhydrides. Chem. Commun. 2012, 48, 7034-7036. (c) Wotal, A. C.; Weix, D. J. Synthesis of functionalized dialkyl ketones from carboxylic acid derivatives and alkyl halides. Org. Lett. 2012, 14, 1476-1479. (d) Cherney, A. H.; Kadunce, N. T.; Reisman, S. E. Catalytic asymmetric reductive acyl cross-coupling: Synthesis of enantioenriched acyclic $\alpha, \alpha$-disubstituted ketones. J. Am. Chem. Soc. 2013, 135, 7442-7445. (e) Jia, X.; Zhang, X.; Qian, Q.; Gong, H. Alkyl-aryl ketone synthesis via nickel-catalyzed reductive coupling of alkyl halides with aryl acids and anhydrides. Chem. Commun. 2015, 51, 10302-10305.

(12) Zuo, Z.; Ahnemqn, D. T.; Chu, L.; Terrett, J. A.; Doyle, A. G.; MacMillan, D. W. C. Merging photoredox with nickel catalysis: Coupling of $\alpha$-carboxyl $\mathrm{sp}^{3}$-carbons with aryl halides. Science 2014, 345, 437-440.

(13) Tellis, J. C.; Primer, D. N.; Molander, G. A. Dual catalysis. Single-electron transmetalation in organoboron cross-coupling by photoredox/nickel dual catalysis. Science 2014, 345, 433-436.

(14) For recent reviews, see: (a) Twilton, J.; Le, C; Zhang, P.; Shaw, M. H.; Evans, R. W.; MacMillan, D. W. C. The merger of transition metal and photocatalysis. Nat. Rev. Chem. 2017, 1, 0052. (b) Milligan, J. A.; Phelan, J. P., Badir, S. O., Molander, G. A. Alkyl carbon-carbon bond formation by nickel/photoredox cross-coupling. Angew. Chem., Int. Ed. 2019, 58, 6152-6163.

(15) (a) Zhang, P.; Le, C.; MacMillan, D. W. C. Silyl radical activation of alkyl halides in metallaphotoredox catalysis: A unique pathway for cross-electrophile coupling. J. Am. Chem. Soc. 2016, 138, 8084-8087. See also for other related examples: (b) Bacauanu, V.; Cardinal, S.; Yamauchi, M.; Kondo, M.; Fernández, D. F.; Remy, R.; MacMillan, D. W. C. Metallaphotoredox difluoromethylation of aryl bromides. Angew. Chem., Int. Ed. 2018, 57, 12543-12548. (c) Zhou, Q.-Q.; Düsel, S. J. S.; Lu, L.-Q.; König, B.; Xiao, W.-J. Alkenylation of unactivated bromides through visible light photocatalysis. Chem. Commun. 2019, 55, 107-110.

(16) Chatgilialoglu, C.; Ferreri, C.; Landais, Y.; Timokhin, V. I. Thirty years of (TMS $)_{3} \mathrm{SiH}$ : A milestone in radical-based synthetic chemistry. Chem. Rev. 2018, 118, 6516-6572.

(17) For a review of silyl radical-mediated transformations under photoredox conditions, see: a) Li, J.-S.; Wu, J. Recent developments in the photo-mediated generation of silyl radicals and their application in organic synthesis. ChemPhotoChem 2018, 2, 839-846. For selected recent applications, see: b) Le, C.; Chen, T. Q.; Liang, T.; Zhang, P.; MacMillan, D. W. C. A radical approach to the copper oxidative addition problem: Trifluoromethylation of bromoarenes. Science 2018, 360, 1010-1014. c) ElMarrouni, A.; Ritts, C. B.; Balsells, J. Silylmediated photoredox-catalyzed Giese reaction: addition of non-activated alkyl bromides. Chem. Sci. 2018, 9, 6639-6646. d) Zhu, J.; Cui, W.-C.; Wang, S.; Yao. Z.-J. Radical hydrosilylation of alkynes catalyzed by Eosin Y and thiol under visible light irradiation. Org. Lett. 2018, 20, 3174-3178. e) Hell, S. M.; Meyer, C. F.; Laudadio, G.;
Misale, A.; Willis, M. C.; Noël, T.; Trabanco, A. A.; Gouverneur, V. Silyl radical-mediated activation of sulfamoyl chlorides enables direct access to aliphatic sulfonamides from alkenes J. Am. Chem. Soc. 2020, 142, 720-725. f) Zhang, Z.; Hu, X. Arylsilylation of electrondeficient alkenes via cooperative photoredox and nickel catalysis. ACS Catal. 2020, 10, 777-782.

(18) $\mathrm{N}$-Acyl-succinimides and glutarimides have been used as privileged amide electrophiles in cross-coupling reactions; see for instance: a) Shi, S.; Szostak, M. Nickel-catalyzed Negishi cross-coupling of $\mathrm{N}$-acylsuccinimides: Stable, amide-based, twist-controlled acyl-transfer reagents via $\mathrm{N}-\mathrm{C}$ activation. Synthesis 2017, 49, 3602 3608. b) Osumi, Y.; Liu, C.; Szostak, M. N-Acylsuccinimides: twistcontrolled, acyl-transfer reagents in Suzuki-Miyaura cross-coupling by N-C amide bond activation. Org. Biomol. Chem. 2017, 15, 8867-8871. c) Meng, G.; Szostak, M. N-Acyl-glutarimides: Privileged scaffolds in amide $\mathrm{N}-\mathrm{C}$ bond cross-coupling. Eur. J. Org. Chem. 2018, 2018, 2352-2365 (review).

(19) It should be pointed out that the mass balance of the starting imide consisted essentially of undefined degradation material. The corresponding decarbonylated coupling product, 4-phenyl-tetrahydropyran, could also be observed in reaction mixtures (GC-MS), though as a very minor co-product.

(20) The slightly lower yield obtained with the glutarimide derivative 1ab may result from higher twist activation and therefore lower stability of $\mathrm{N}$-acyl-glutarimides compared to $\mathrm{N}$-acyl-succinimides. For structural and mechanistic information on twisted amide electrophiles, see: a) Pace, V.; Holzer, W.; Meng, G.; Shi, S.; Lalancette, R.; Szostak, R.; Szostak, M. Structures of highly twisted amides relevant to amide $\mathrm{N}-\mathrm{C}$ cross-coupling: Evidence for ground-state amide destabilization. Chem. Eur. J. 2016, 22, 14494-14498. b) Szostak, R.; Szostak, M. $N$-Acyl-glutarimides: Resonance and proton affinities of rotationally-inverted twisted amides relevant to $\mathrm{N}-\mathrm{C}(\mathrm{O})$ cross-coupling. Org. Lett. 2018, 20, 1342-1345.

(21) Interestingly, $\alpha$-alkoxy- and $\alpha$-amino-ketones have been made accessible using alkyltrifluoroborates coupling partners (see ref 7). In contrast, however, no example involving simple primary alkyltrifluoroborates was documented in this work. Of note, in a related paper by the same group reporting the use of acyl chlorides as electrophilic partners for this transformation, it was stated that primary alkyltrifluoroborates were not suitable substrates, owing to an unfavorable redox potential (see ref $8 b$ )

(22) a) Reina, A.; Krachko, T.; Onida, K.; Bouyssi, D.; Jeanneau, E.; Monteiro, N.; Amgoune, A. Development and mechanistic investigations of a base-free Suzuki-Miyaura cross-coupling of $\alpha, \alpha$-difluoroacetamides via $\mathrm{C}-\mathrm{N}$ bond cleavage. ACS catal. 2020, 10 , 2189-2197. For an overview of the preparation, uses, and biological activities of $\alpha, \alpha$-difluoroketones, see: b) Pattison, G. Methods for the synthesis of $\alpha, \alpha$-difluoroketones. Eur. J. Org. Chem. 2018, 2018, $3520-3540$

(23) An authentic sample of $\mathbf{4}$ was obtained from the reaction of succinimide with commercially available chlorotris(trimethylsilyl)silane. See Supporting Information. 
